\title{
Body Composition Changes Associated With Methadone Treatment
}

\author{
Gamal E. Sadek, ${ }^{1}$ Simon Chiu, ${ }^{2}$ and Zack Z. Cernovsky ${ }^{1,2,}$ \\ ${ }^{1}$ Methadone Clinic, Ontario, Canada \\ ${ }^{2}$ Department of Psychiatry, University of Western Ontario, Ontario, Canada \\ *Corresponding author: Zack Z. Cernovsky, Department of Psychiatry, University of Western Ontario, Ontario, Canada. Tel/Fax:+1-5194718049, E-mail: zcernovs@uwo.ca
}

Received 2015 February 4; Revised 2015 February 26; Accepted 2015 March 4.

\begin{abstract}
Background: Methadone is associated with a statistically significant increase in BMI in the first 2 years of treatment.

Objectives: To evaluate the changes of body composition (bone mass, \% fat, \% muscle mass, \% water, and basal metabolic rate) related to this increase.

Patients and Methods: Changes in body composition were monitored, via bioelectrical impedance, in 29 patients in methadone treatment for opiate dependency (age 18 to 44 , mean $=29.3, \mathrm{SD}=7.0,13$ men, 16 women).

Results: Within one year from admission to treatment, a statistically significant $(\mathrm{t}$-tests, $\mathrm{P}<0.05)$ increase was noted in their body mass index (BMI), \% of body fat, average body mass, and average basal metabolic rate, and relative decrease in their \% of muscle mass and \% of bone mass. Neither absolute bone mass nor muscle mass changed significantly.

Conclusions: Physicians involved in care of methadone patients should recommend dietary and lifestyle changes to improve their overall health.
\end{abstract}

Keywords: Methadone, Body Mass Index, Obesity

\section{Background}

Clinical lore suggests that methadone treatment for opiate dependency leads to increase in body mass, however, very few studies measured this statistically. In the Slovak Republic, Okruhlica and Slezakova (1) followed 274 methadone patients for a year, starting with their admission to treatment. All were classified via body mass index (BMI). A significant increase $(\mathrm{P}<0.001)$ was noted on all BMI categories from admission to one year follow up. The proportion of those underweight decreased from 10 to $5 \%$, the proportion of normal weight changed from $72 \%$ to $58 \%$, the proportion in the overweight category increased from 15 to $29 \%$, and the proportion of obese patients increased from 3 to $8 \%$. However, even at the one year follow up, these patients still remained significantly below proportions of these BMI categories in the general population (4\%, $49 \%, 34 \%$ and $13 \%, \mathrm{P}<0.001)$. Similarly, the Polish study by Szpanowska-Wohn et al. (2) noted an increase in average body mass from $71.7 \mathrm{~kg}$ to $75.7 \mathrm{~kg}$ within 9 months following entry to methadone treatment. A study by Montazerifar et al. (3) noted a significant increase in BMI already within the first 8 weeks on admission to methadone treatment. Within the 8 weeks, the average weight of patients treated by Montazerifar's team showed a statistically significant increase from $61.4 \mathrm{~kg}$ on admission to treatment to $65.3 \mathrm{~kg}$ which corresponded to a BMI increase from 21.4 to 23.0. The rapid weight increase within the first 8 weeks is remarkable, but was perceived as medically valuable with respect to those underweight and malnourished. The proportion of the underweight patient decreased by half. However, the proportion of those in the obese category doubled. As shown by Montazerifar et al. (3), the percentages of underweight, overweight and obese patients were $27.3 \%, 18.2 \%$ and $3.6 \%$, respectively before methadone treatment, and $12.7 \%, 18.2 \%$ and $7.2 \%$ at the end of the 8 weeks. A subsequent US study of 69 methadone patients by Fenn et al. (4) also found a significant increase in BMI from admission to follow up. The data published by Fenn's team indicated a mean increase by $8.1 \mathrm{~kg}$ which corresponded, on average, to an increase of $10 \%$ in body weight. The average BMI in a study by Fenn et al. (4)increased from 27.2 (overweight category) to 30.1 (lowest section of the obese category).

Okruhlica and Slezakova (5) examined the BMI of 42 methadone patients over 4 years. The BMI significantly increased in the first year of treatment and also from the first to the second year; however, no significant change was noted in the subsequent 2 years. This suggests that the BMI stabilized. The correlation of methadone dose to BMI was not significant at the end of this follow up. According to data in Okruhlica and Slezakova (5), the weight of their 42 patients at the end of the 4 year follow up did not differ from the measures in the general local population. At that point in the follow up, there was no significant correlation between the daily dose of metha-

Copyright (c) 2016, Zahedan University of Medical Sciences. This is an open-access article distributed under the terms of the Creative Commons Attribution-NonCommercial 4.0 International License (http://creativecommons.org/licenses/by-nc/4.0/) which permits copy and redistribute the material just in noncommercial usages, provided the original work is properly cited. 
done and the patients' BMI. Okruhlica and Slezakova (5) hypothesized that the weight gain of their patients in opiate substitution treatment is most probably a consequence of the changes in their lifestyle and not the result of direct adverse pharmacological effect of methadone medication. The findings by Okruhlica and Slezakova (5), if replicated, are of crucial medical importance because they suggest that the rapid weight increase such as the twofold increase of patients within the obese category observed by Montazerifar et al. (3) within the time span as short as only 8 weeks does not continue beyond the first or the second year of methadone treatment and is perhaps more related to changes in lifestyle than to pharmacological properties of methadone.

In our effort to reduce the risk of metabolic syndrome, it is important to know which parameters of body composition (e.g., \% body fat versus \% muscle mass) are primarily affected by the weight increase observed in the first year of methadone treatment.

\section{Objectives}

We measured, via bioelectrical impedance, the changes in body composition and in the body mass index (BMI) within one year following admission to methadone treatment.

\section{Patients and Methods}

On their admission and also at one year follow-up, 29 methadone maintenance patients (age 18 to 44 , mean $=29.3, S D=$ $7.0,13$ men, 16 women) completed the symptom check list 90 revised (SCL-90-R) and we measured their weight, BMI, and body composition (muscle mass, bone mass, \% of fat, \% of water, and basal metabolic rate,) via bioelectrical impedance, using Tanita Ironman body composition monitor BC554.

\section{Results}

Within one year following their admission to methadone treatment, our patients showed a significant decrease ( $\mathrm{t}$ tests, $\mathrm{P}<0.05$, 2-tailed) on SCL-90-R scales of depression, anxiety, and overall psychopathology. A significant increase was noted in their mean BMI (increase from 24.1, SD $=4.1$ to $26.3, \mathrm{SD}=4.8$ ), mean body mass (from $71.8 \mathrm{~kg}$, SD $=14.4$ to $78.3 \mathrm{~kg}, \mathrm{SD}=15.9$ ), \% fat (from $25.3 \%$ of total body mass, $\mathrm{SD}=10.0$ to $30.6 \%, \mathrm{SD}=9.3$ ), and basal metabolic rate (from 1593.4, $\mathrm{SD}=267.0$ to $1633.5, \mathrm{SD}=288.6$ ) and a significant decrease in \% of muscle mass (from $71.0 \%$ of body mass, $\mathrm{SD}=9.6$ to $65.8 \%, \mathrm{SD}=8.9$ ), in \% of water (from $52.0 \%$, $\mathrm{SD}=6.1$ to $48.8 \%, \mathrm{SD}=5.5$ ) and in \% bone mass (from $3.7 \%, \mathrm{SD}$ $=0.5$ to $3.5 \%, \mathrm{SD}=0.5$ ). Absolute measures of bone and of muscle mass have not noticeably changed.

\section{Discussion}

Neither absolute muscle mass nor absolute bone mass changed significantly within one year of admission to methadone treatment. The overall body mass has increased chiefly due to an increase in the proportion of body fat.
Hopefully, future studies might clarify the relative contribution of biochemical, environmental, and lifestyle mechanisms responsible for the increase in percent of body fat.

The patients' average BMI increased from the normal to overweight category. On the one hand, this points to an increased risk of metabolic syndrome and associated conditions. For example, with respect to insuline resistance, a recent US study found that diabetes mellitus was significantly more common in patients receiving opiate dependence treatment via methadone than via buprenorphine (6). In methadone patients with sleep difficulties, obstructive sleep apnea was more common in those with higher BMI and longer duration of methadone maintenance treatment (7). On the other hand, methadone treatment helps the patients to avoid conflicts with the law and dramatically increases their chances of long term survival. An Australian retrospective study of a cohort of 307 heroin addicts indicated that these patients were nearly three times as likely to die if outside of methadone maintenance treatment than in it. A retrospective analysis of UK data showed that the total number of convictions, theft and fraud convictions, and weeks spent in prison per year were reduced by $39.3 \%, 52.17 \%$, and $82.8 \%$, respectively (8). A recent Chinese neta-analytic study of the total of 30,239 patients found a decrease in arrest rates from $13.1 \%$ to $4.3 \%$ and increase in employment rates from $26.4 \%$ to $59.8 \%$ within 12 months following admission to methadone treatment (9). Furthermore, some comparative studies of methadone and buprenorphine indicate that the former is associated with higher treatment retention rates (10). Such data show that medical, societal, and economic benefits of methadone treatment outweigh the potential adverse side effects. However, physicians involved in care of methadone patients should preventively recommend dietary and lifestyle changes to improve their overall health.

\section{Acknowledgments}

We thank the patients in the methadone clinic for their participation in this medical study.

\section{Footnote}

Authors' Contribution:Study concept and design: Gamal E. Sadek, Zack Z. Cernovsky, Simon Chiu; acquisition of data: Zack Z. Cernovsky and Gamal E. Sadek; analysis and interpretation of data: Zack Z. Cernovsky and Simon Chiu; drafting of the manuscript: Zack Z. Cernovsky; critical revision of the manuscript for important intellectual content: Simon Chiu, Gamal E. Sadek; statistical analysis: Zack Z. Cernovsky.

\section{References}

1. Okruhlica L, Slezakova S. [Weight gain among the patients in methadone maintenance program as come-back to population norm]. Cas Lek Cesk. 2008;147(8):426-30. [PubMed: 18777802]

2. Szpanowska-Wohn A, Kolarzyk E, Pach D, Targosz D. [Intake of 
nutrients in daily nutritional ratios by opiate dependent persons during methadone maintenance therapy]. Przeglad lekarski. 2003;61(4):332-8. [PubMed:15521596]

3. Montazerifar F, Karajibani M, Lashkaripour K. Effect of methadone maintenance therapy on anthropometric indices in opioid dependent patients. Int J High Risk Behav Addict. 2012;1(3):100-3. doi:10.5812/ijhrba.4968. [PubMed: 24971244]

4. Fenn JM, Laurent JS, Sigmon SC. Increases in body mass index following initiation of methadone treatment.J Subst Abuse Treat. 2015;51:59-63. doi: 10.1016/j.jsat.2014.10.007. [PubMed: 25441923]

5. Okruhlica L, Slezakova S. [Weight changes of patients in methadone maintenance treatment during four years period]. Cas Lek Cesk. 2012;151(8):389-91. [PubMed: 23101891]

6. Fareed A, Byrd-Sellers J, Vayalapalli S, Drexler K, Phillips L. Predictors of diabetes mellitus and abnormal blood glucose in patients receiving opioid maintenance treatment. Am J Addict. 2013;22(4):411-6. doi:10.111/j.1521-0391.2013.12043.x. [PubMed: 23795882]

7. Sharkey KM, Kurth ME, Anderson BJ, Corso RP, Millman RP, Stein
MD. Obstructive sleep apnea is more common than central sleep apnea in methadone maintenance patients with subjective sleep complaints. Drug Alcohol Depend. 2010;108(1-2):77-83. doi: 10.1016/j.drugalcdep.2009.11.019. [PubMed: 20079978]

8. Keen J, Rowse G, Mathers N, Campbell M, Seivewright N. Can methadone maintenance for heroin-dependent patients retained in general practice reduce criminal conviction rates and time spent in prison? Br J Gen Pract. 2000;50(450):48-9. [PubMed:10695069]

9. Sun HM, Li XY, Chow EP, Li T, Xian Y, Lu YH, et al. Methadone maintenance treatment programme reduces criminal activity and improves social well-being of drug users in China: a systematic review and meta-analysis. BMJ Open. 2015;5(1):e005997. doi: 10.1136/bmjopen-2014-005997. [PubMed: 25573521]

10. Fischer G, Gombas W, Eder H, Jagsch R, Peternell A, Stuhlinger $\mathrm{G}$, et al. Buprenorphine versus methadone maintenance for the treatment of opioid dependence. Addiction. 1999;94(9):1337-47. [PubMed:10615719] 